\title{
Commonly cited incentives in the community implementation of the emergency maternal and newborn care study in western Kenya
}

\author{
*Gisore $\mathrm{P}^{1,2}$, Rono $\mathrm{B}^{2}$, Marete $\mathrm{I}^{1,2}$, Nekesa-Mangeni $\mathrm{J}^{2}$, Tenge $\mathrm{C}^{1,2}$, Shipala $\mathrm{E}^{2}$, Mabeya $\mathrm{H}^{1,2}$, Odhiambo \\ $\mathrm{D}^{2}$, Otieno $\mathrm{K}^{2}$, Bucher $\mathrm{S}^{3}$, Makokha $\mathrm{C}^{2}$, Liechty $\mathrm{E}^{3}$, Esamai $\mathrm{F}^{1,2}$
}

1. School of Medicine, Moi University, Kenya

2. Moi Teaching and Referral Hospital, Eldoret, Kenya

3. Indiana University, Indianapolis, USA

\begin{abstract}
Background: Mortality of mothers and newborns is an important public health problem in low-income countries. In the rural setting, implementation of community based education and mobilization are strategies that have sought to reduce these mortalities. Frequently such approaches rely on volunteers within each community.

Objective: To assess the perceptions of the community volunteers in rural Kenya as they implemented the EmONC program and to identify the incentives that could result in their sustained engagement in the project.

Method: A community-based cross sectional survey was administered to all volunteers involved in the study. Data were collected using a self-administered supervision tool from all the 881 volunteers.

Results: 881 surveys were completed. 769 respondents requested some form of incentive; $200(26 \%)$ were for monetary allowance, $149(19.4 \%)$ were for a bicycle to be used for transportation, $119(15.5 \%)$ were for uniforms for identification, 88 $(11.4 \%)$ were for provision of training materials, $81(10.5 \%)$ were for training in Home based Life Saving Skills (HBLSS), $57(7.4 \%)$ were for provision of first AID kits, and 39(5\%) were for provision of training more facilitators, 36(4.7\%) were for provision of free medication.

Conclusion: Monetary allowances, improved transportation and some sort of identification are the main incentives cited by the respondents in this context.

Key words: Incentives, motivation, community health workers, community implementation, community participation, Emergency Obstetric and Neonatal Care.

African Health Sciences 2013; 13(2):461 - 468 http:/ /dx.doi.org/10.4314/ahs.v13i2.37
\end{abstract}

\section{Introduction}

While the health sectors of developing countries recognize the need for paid Community Health Workers (CHWs) as recommended by World Health Organization (WHO), only a few, such as India, have in place this cadre of workers. The majority of countries in Africa, including Kenya, use volunteers from the communities for implementing community based programs. There is sufficient experience with CHWs as implementers of pre-designed programs, and their incentives have been categorized. This cadre of community volunteers are motivated by recognition, provision of tools, monetary payments and training. Long term retention of volunteers in these positions has been difficult. The use of incentives for retention of volunteer health workers

\section{*Corresponding author: \\ Peter Gisore \\ School of Medicine, Moi University \\ 4606 - 3100, Eldoret, Kenya \\ Tel: +254-725-619-549 \\ E-mail: gisore2007@gmail.com}

African Health Sciences Vol 13 Issue 2 June 2013 in low income settings remains controversial at all levels of the healthcare including the community level health programs ${ }^{1-6}$, In addition, publications on incentives for volunteers, whose activities included mobilizing communities in a process of leveraging community owned resource to implement maternal and newborn health interventions, are few in the literature.

The Global Network for Women's and Children's Health Research (GNWCHR) is a multi-country, multi-site research network that seeks to understand the causes of perinatal morbidity and mortality. This research network was undertaking studies for reduced maternal and neonatal mortality, through increasing and improving the quality of obstetric and neonatal care in communities ${ }^{7}$. They had two independent but interlinked on-going studies. First, the Maternal and Neonatal Birth (MNH) Registry registered all pregnancies, births and deaths of mothers and neonates within the defined geographic area of the study. The second is the Emergency Obstetric and Neonatal Care (EmONC) study. 
The EmONC study had volunteer-based teams, working within these geographic clusters to address the linkage between the community and the health facility (Health System) in the care for mothers and their newborns. These volunteers were villagers, nominated by fellow villagers, through a process led by the local administrators. They were to lead the community in finding home-grown solutions to the Maternal and Newborn Health problems. The cluster study team of EmONC supported these nominees by training them on how to facilitate dialogue in the community for planning, acting and evaluating their activities. In addition, they trained them on Home Based Life Saving Skills (HBLSS). The countries participating in this study included Kenya, Zambia, Guatemala, Argentina, Pakistan, India, and others. When retaining volunteers became difficult to do in Kenya, the country study team sought to find the context specific incentives to use to reduce attrition. This paper is based on anonymous retrospective review of this routine data. The protocol and related processes for the parent study was published ${ }^{8}$ and a summary has been included in the methods section of this article.

\section{Methods}

\section{EMONC Study design and process}

The EMONC study comprised of three interventions:

1.) Home Based Life Saving Skills (HBLSS) aimed at training community birth attendants (skilled and unskilled) to recognize problems, stabilize and refer pregnant women and their newborns to appropriate health care facilities

2.) Community Mobilization (CM), aimed to educate and mobilize the local community to identify resources and solutions within the community to improve maternal and neonatal mortality, with special emphasis on pregnant women and their families

3.) Health Facility Improvement (HFI) aimed at ensuring that once a pregnant woman and her newborn reached the referral facility, appropriate services were available.

Implementation of the first and second arms relied upon lay personnel, most of whom were volunteers, while the third arm relied upon health-care professionals. The first two arms were designed to be done through leveraging each community's own human and material resources. Thus the cadre of community volunteers was the main human resource implementing these components. These volunteers joined cluster committees, village committees and core groups as described in the study protocol process publication ${ }^{8}$.

The cluster committees held regular planning meetings. Their activities included formation of the village committees and support of their subsequent activities, facilitation of lay persons on the discussion of newborn and maternal mortality events (mortality audits), support of the activities of volunteer facilitators and overseeing community mobilization activities. Those who were most affected and interested in maternal and newborn health in the villages joined core groups. The Village Health Committees provided support to all the core group activities. To build capacity for their activities, these volunteers received training on Home Based Life Saving Skills (HBLSS) to recognize danger signs and stabilize the mothers and newborn and refer them to the health facility. They also receive training on Community Action Cycle (CAC) for community mobilization activities ${ }^{9-12}$. The activities in the CAC included preparing to mobilize, exploring, planning, acting and evaluating action plans. The core groups were formed by community members committed to EmONC activities, and used the CAC to mobilize the village community members to participate effectively in EmONC activities.

The third arm relied upon obstetricians and nurses, trained using a standardized curriculum, providing training in the health facilities to the health care providers. This was meant to improve the quality of service. To standardize the facilities ability to provide services, the study provided basic equipment including thermometers, blood pressure sphygmomanometers and magnesium sulphate to the health facilities. The EmONC study was thus designed to introduce maternal and newborn survival interventions that can be sustained by the community.

Within the first year of implementing the protocol in Kenya, $40 \%$ of the initial members of the Cluster Committees and volunteer facilitators had dropped out. It then became obvious to all that attrition of the lay volunteers was a major contributor to delays in completing the full CAC. Even the study investigators, who had to train the new workers, had higher than anticipated cost for training new volunteers. In order to address this challenge, and as part of the CAC, the potential locally available, feasible and applicable incentives were sought. 


\section{Study site}

The Kenya EmONC study area was located in the western Kenya districts of Busia, Bungoma, Mumias and Teso (figure 1). This region of western Kenya is rural agrarian and has $50 \%$ of the population being in the last 2 levels of the index for household durable goods, making it among the poorest rural area in
Kenya $^{17}$. Most families relied upon subsistence farming. Each cluster was served by one government health facility capable of conducting deliveries, as well as several lower level health facilities or dispensaries. In addition there are a few mission hospitals also providing delivery service.

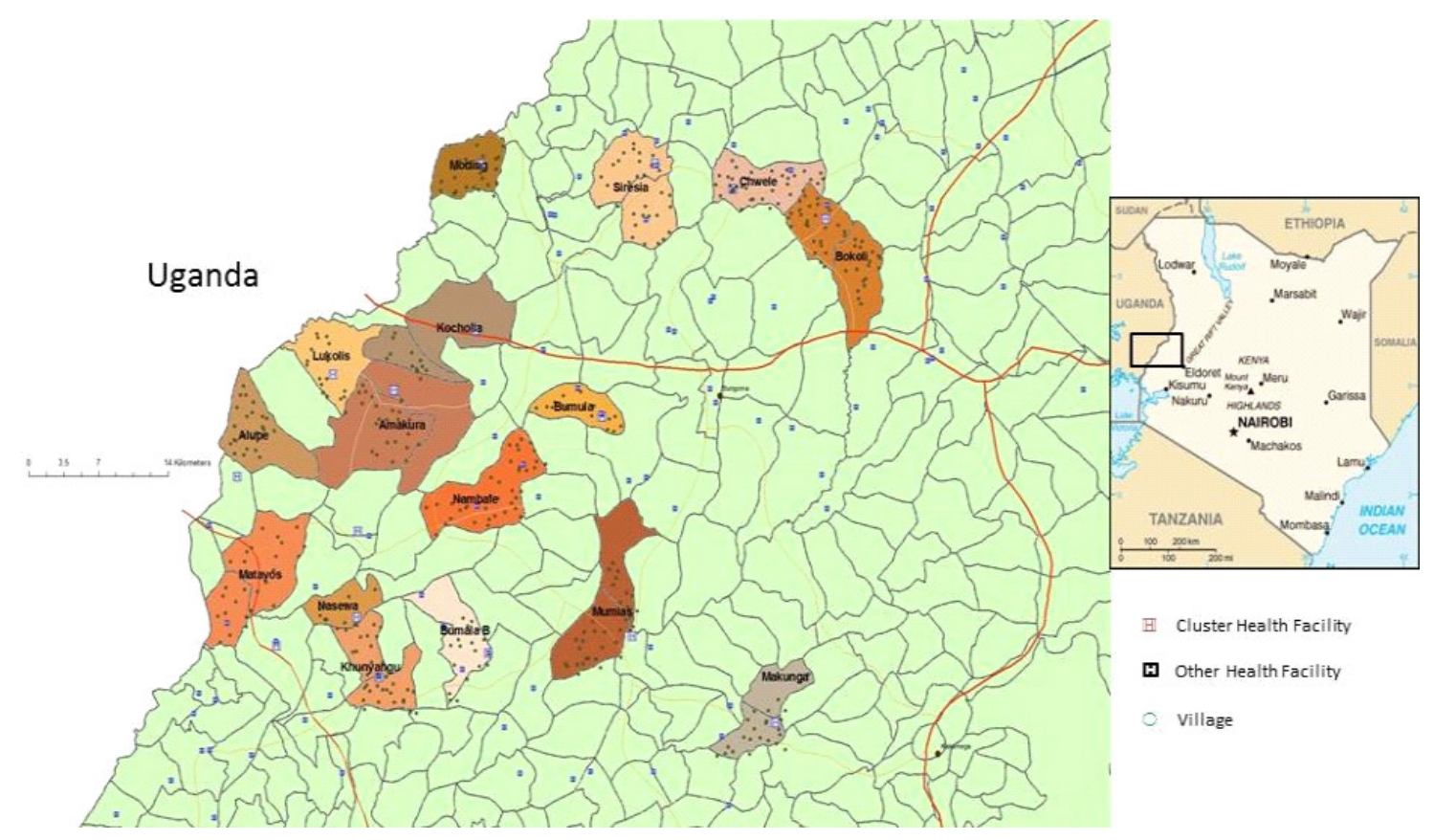

Figure 1: Map of the EmONC area. The area is located in western Kenya, adjacent to the Uganda border

\section{Study population on incentives}

The participants in this survey were volunteers in the EmONC program. They were volunteers in the various community-based cluster committees. They participated either as high-up management members (Cluster Committee Members), or as village-based management members (Village Committee Members) or core group leadership (Volunteer Facilitators). All respondents had received training on HBLSS and CAC to guide their organizing the community for action, through the preparing to mobilize, exploring, planning, acting and evaluating action plans components. All respondents could read and write in English and Kiswahili.

All respondents were aware of the issue of lack of incentives and the accruing attrition since it had come up in many of CAC meetings in which they participated. After consensus was built in these meetings to address the problem, they proposed answering a self-administered questionnaire, to determine the nature of incentives they considered appropriate in their context.

\section{Data collection on incentives}

The questionnaire was designed by the Kenya EMONC investigators limiting the content to what the lay volunteers determined as acceptable including a few open-ended questions. The volunteers were given the questionnaires to complete and returned the completed questionnaires after 3 months (November 2009 and January 2010).

\section{Data analysis}

To extract this data, tables were constructed for each of the closed ended questions. Themes in the open ended answers were developed after being evaluated for relevance by the investigators. The data was entered into the Epidata program (EpiData Software, EpiData Association, Odense Denmark) and analysed using frequencies and cross tabulations.

\section{Results}

Based on the number of volunteers in the study area, 881 questionnaires were distributed and all were filled 
and returned. There were a total of 881 participants, $64 \%$ were females and $36 \%$ males. The age of the respondents ranged from 20 to over 50 years, $70 \%$ being below 40 years of age as indicated in table 1 . The largest majority ( $98 \%$ of the respondents) had a secondary education or less as shown in table 2 . Younger volunteers were more highly educated than older volunteers.

Table 1: Gender distribution in the various age groups

\begin{tabular}{llllll}
\hline \multicolumn{7}{c}{ Age of participants (years) N (\%) } \\
& $\mathbf{2 0 - 3 0}$ & $\mathbf{3 1 - 4 0}$ & $\mathbf{4 1 - 5 0}$ & $\mathbf{5 1}$ & Total \\
\hline Male & $52(16)$ & $133(42)$ & $85(27)$ & $50(16)$ & 320 \\
Female & $233(2)$ & $199(36)$ & $93(17)$ & $32(6)$ & 557 \\
Total & 285 & 332 & 178 & 82 & 877 \\
\hline
\end{tabular}

*Age group of 4 respondents was missing.

Note that the percentages in the table are as follows: The middle rows add up to $100 \%$ for each gender

Table 2: Education levels of the volunteers

\begin{tabular}{lcccc}
\hline Years of education $\mathbf{0 - 8}$ & $\mathbf{9 - 1 2}$ & $\mathbf{> 1 2}$ & Total \\
\hline 141 & 132 & 12 & 285 & \\
132 & 191 & 7 & 330 & \\
88 & 88 & 2 & 178 & \\
43 & 39 & 0 & 82 & \\
Total & & & & 881 \\
\hline
\end{tabular}

Did not respond to years of education question 6

The respondents' opinions were sought on how the EmONC program has been useful to the community (table 3 ). Five hundred and ninety nine responses $(55.1 \%)$ cited improved level of understanding (health education) through HBLSS activities, 197 (16.5\%) cited reduction in mortality, $128(10.7 \%)$ cited health facility improvement, and $205(17.2 \%)$ cited other outcomes.

The volunteer facilitators' opinions on which incentives they wished to be provided were varied. $26 \%$ mentioned a monetary allowance as their preferred motivation or incentive. Others preferred different incentives including provision of a bicycle $(19.4 \%)$, provision of uniform and identification badge $(15.5 \%)$, supply of training materials $(11.4 \%)$, training in Home Based Life Saving Skills (10.5\%), provision of first aid kit $(7.4 \%)$, training of more facilitators (5\%) and supply of free medicines (4.7\%) table 4.
Table 3: Responses to the question: How the EmONC program has been useful to the community

\begin{tabular}{ll}
\hline Response & $\mathbf{N ( \% )}$ \\
\hline $\begin{array}{l}\text { Mothers health education } \\
\text { (HBLSS related activities) }\end{array}$ & $599(55)$ \\
$\begin{array}{l}\text { Improved health facility obstetric } \\
\text { care }\end{array}$ & $128(11)$ \\
$\begin{array}{l}\text { Emergency delivery materials } \\
\text { Education (Family planning) }\end{array}$ & $68(6)$ \\
$\begin{array}{l}\text { Reduced mortality (mothers, } \\
\text { babies) }\end{array}$ & $197(17)$ \\
$\begin{array}{l}\text { Reduction of home deliveries } \\
\text { Increased ANC Attendance }\end{array}$ & $61(5)$ \\
\hline
\end{tabular}

Table 4: Incentives requested by facilitators

\begin{tabular}{|c|c|}
\hline Response & $\mathrm{N}(\%)$ \\
\hline \multicolumn{2}{|l|}{ Personal incentives } \\
\hline Monetary Allowance & $200(26)$ \\
\hline Bicycles & $149(20)$ \\
\hline Uniform & $119(16)$ \\
\hline Training materials & $88(11)$ \\
\hline HBLSS training & $81(11)$ \\
\hline First AID Kits & $57(7)$ \\
\hline Free medication & $36(5)$ \\
\hline More Facilitators & $39(5)$ \\
\hline \multicolumn{2}{|l|}{ Community incentives } \\
\hline $\begin{array}{l}\text { Increase in primary health } \\
\text { facilities. }\end{array}$ & $301(30)$ \\
\hline Ambulances & $147(15)$ \\
\hline \multicolumn{2}{|c|}{ Emergency delivery materials $80(8)$} \\
\hline Subsidized Medication & $52(5)$ \\
\hline Continued Health Education & $255(26)$ \\
\hline Food Rations to the poor & $43(4)$ \\
\hline Mobile Antenatal Clinics & $99(10)$ \\
\hline
\end{tabular}

About $20.9 \%$ of the responses from the facilitators indicated a need for more primary health facilities, $18.8 \%$ desired more health education, $15 \%$ desired an ambulance, $10.1 \%$ desired mobile antenatal clinic, $10 \%$ desired maternity wards to be constructed and $25 \%$ had varied needs (table 4 ).

When analysis by age group (5 year intervals) was done, there was significant variation in response based on age category and were as follows as shown in table 5 . 
Table 5: Positive responses (desire for) by age, showing the number of respondents and their respective percentages

\begin{tabular}{|c|c|c|c|c|c|c|c|c|}
\hline Age in years & $20-25$ & $26-30$ & $31-35$ & $36-40$ & $41-45$ & $46-50$ & $>51$ & $\begin{array}{l}* * \mathrm{P}- \\
\text { value }\end{array}$ \\
\hline $\mathrm{n}$ & 125 & 152 & 174 & 133 & 98 & 71 & 74 & \\
\hline Allowances & $12 \%$ & $18.4 \%$ & $28.7 \%$ & $28.6 \%$ & $24.5 \%$ & $35.7 \%$ & $27.0 \%$ & 0.001 \\
\hline Uniforms & $12.8 \%$ & $12.5 \%$ & $16.7 \%$ & $18 \%$ & $15.3 \%$ & $12 . \%$ & $9.5 \%$ & 0.606 \\
\hline bicycles & $11.2 \%$ & $16.4 \%$ & $20.7 \%$ & $21.1 \%$ & $18.4 \%$ & $22.9 \%$ & $16.2 \%$ & 0.310 \\
\hline $\begin{array}{l}\text { Desire to learn more } \\
\text { HBLSS }\end{array}$ & $8 \%$ & $9.2 \%$ & $10.3 \%$ & $13.5 \%$ & $8.2 \%$ & $12.9 \%$ & $14.9 \%$ & 0.572 \\
\hline First AID Kit & $5.6 \%$ & $2 \%$ & $8.6 \%$ & $7.5 \%$ & $5.1 \%$ & $10 \%$ & $13.5 \%$ & 0.034 \\
\hline Free Medicines & $4 \%$ & $0.7 \%$ & $4.6 \%$ & $6 \%$ & $4.1 \%$ & $5.7 \%$ & $8.1 \%$ & 0.184 \\
\hline $\begin{array}{l}\text { More HBLSS } \\
\text { facilitators }\end{array}$ & $3.2 \%$ & $4 \%$ & $4 \%$ & $6 \%$ & $2 \%$ & $4.3 \%$ & $10.8 \%$ & 0.169 \\
\hline $\begin{array}{l}\text { Ambulance services } \\
\text { during delivery }\end{array}$ & $11.8 \%$ & $18.1 \%$ & $19.6 \%$ & $19.9 \%$ & $12.4 \%$ & $23.9 \%$ & $11.1 \%$ & 0.108 \\
\hline $\begin{array}{l}\text { Emergency provision } \\
\text { during delivery }\end{array}$ & $7.1 \%$ & $9.7 \%$ & $8.8 \%$ & $9.6 \%$ & $9.5 \%$ & $4.2 \%$ & $16 \%$ & 0.283 \\
\hline $\begin{array}{l}\text { Subsidized medicines } \\
\text { and mosquito nets }\end{array}$ & $7.1 \%$ & $3.2 \%$ & $4.9 \%$ & $6.8 \%$ & $2.4 \%$ & $45.6 \%$ & $14.8 \%$ & 0.014 \\
\hline Mobile Clinics & $13.4 \%$ & $12.9 \%$ & $11.5 \%$ & $8.2 \%$ & $17.1 \%$ & $7 \%$ & $11.4 \%$ & 0.214 \\
\hline $\begin{array}{l}\text { Health Education } \\
\text { and Capacity building }\end{array}$ & $19.7 \%$ & $12.9 \%$ & $19.8 \%$ & $26 \%$ & $21.9 \%$ & $21.1 \%$ & $133.3 \%$ & 0.014 \\
\hline $\begin{array}{l}\text { Food rations to the } \\
\text { poor }\end{array}$ & $7.9 \%$ & $1.9 \%$ & $4.9 \%$ & $4.8 \%$ & $3.8 \%$ & $1.4 \%$ & $11.1 \%$ & 0.029 \\
\hline Training Centres & $9.4 \%$ & $7.1 \%$ & $9.3 \%$ & $8.2 \%$ & $8.5 \%$ & $8.5 \%$ & $11.1 \%$ & 0.03 \\
\hline
\end{tabular}

Allowances, p value 0.001 , range $12 \%$ to $35 \%$, highest cited in the age category $31-50$ years compared to both younger and older age groups. First aid kit, $\mathrm{p}$ value 0.034 , range $2 \%$ to $13.5 \%$, highest cited in age group $>51$ years and lowest in the 26-30 years. Subsidized medicines and nets, $\mathrm{p}$ value 0.014 , range $2.9 \%$ to $14.8 \%$, highest cited in age group $41-45$ years and lowest in the $20-25$ years.

Health education and capacity building, p value 0.014 , range $19.7 \%$ to $33.3 \%$, highest in $>51$ years and lowest in 20-25 years.

Provision of food rations, $\mathrm{p}$ value 0.03 , range from one out of seventy one responses to $11.1 \%$, highest in $>51$ years and lowest in $46-50$ years. There were no age based difference for desire for uniforms, bicycles, HBLSS training, free medicines, training more facilitators, ambulance services, emergency delivery materials, mobile clinics and training centres. When analysis by gender as shown in table 6 was done, the findings with statistical difference (there was significant variation in response based on age category) were as follows:

Bicycles, P value 0.05, Males 22.1\% and Females $15.7 \%$.

Field Materials. P value 0.003, Males $15.0 \%$ and $8.2 \%$. More primary health facilities, $\mathrm{P}$ value 0.029 , Males $27.8 \%$ and Females $21.2 \%$ Food ratios, P-value 0.018. Males 7.2\% and Females 3.6\%

There was no gender based difference for allowances, uniform, first aid kit, HBLSS training, free medicines, more facilitators, more facilitators, ambulance and transport, maternity wards, delivery materials, mobile clinics and training centres. 
Table 6: Positive responses (desire for) by gender. Showing the number of respondent* and their respective percentages

\begin{tabular}{llll}
\hline Gender & Males & Females & P value \\
\hline Allowances & $79 / 294(26.9 \%)$ & $121 / 534(22.7 \%)$ & 0.203 \\
Uniforms & $46 / 294(15.6 \%)$ & $75 / 534(14 \%)$ & 0.539 \\
Bicycles & $65 / 294(22.1 \%)$ & $84 / 534(15.7 \%)$ & 0.24 \\
Desire to learn more HBLSS & $29 / 294(9.9 \%)$ & $52 / 534(9.7 \%)$ & 1.0 \\
First AID Kit & $23 / 294(7.8 \%)$ & $34 / 534(6.4 \%)$ & 0.474 \\
Free Medicines & $16 / 294(5.4 \%)$ & $20 / 534(3.7 \%)$ & 0.166 \\
More HBLSS facilitators & $19 / 294(6.5 \%)$ & $20 / 514(3.7 \%)$ & 0.057 \\
Ambulance services during delivery & $51 / 318(16 \%)$ & $96 / 551(17.4 \%)$ & 0.639 \\
Emergency provision during delivery & $34 / 318(10.7 \%)$ & $47 / 551(8.5 \%)$ & 0.333 \\
Subsidized medicines and Mosquito nets & $29 / 318(9.1 \%)$ & $23 / 551(4.2 \%)$ & 0.004 \\
Mobile clinics & $36 / 318(11.3 \%)$ & $64 / 551(11.6 \%)$ & 0.913 \\
Health Education and Capacity building & $89 / 318(28 \%)$ & $95 / 551(28 \%)$ & $<0.0001$ \\
Food rations to the poor & $23 / 318(7.2 \%)$ & $29 / 551(4.9 \%)$ & 0.023 \\
Training Centres & $30 / 318(9.4 \%)$ & $42 / 551(7.4 \%)$ & \\
\hline
\end{tabular}

\section{Discussion}

Allowances, bicycles, identification badges and training were cited as the most desired incentives for the volunteers in the EmONC study. While these key incentives were generally similar to those reported in other studies ${ }^{1,16}$, these were specific to the context of the program and population. Though usually unsustainable, monetary incentives were the most cited $(26 \%)$ by the respondents. Bicycle transport was cited by $19.4 \%$, followed by some form of identification $(15.5 \%)$, and more training $(11.4 \%)$. The high rating of bicycle transport might be due to the fact that the EmONC study implementation is associated with significant movement within the villages. Bicycle transport was the main mode of short distance travel in the study area.

There is lack of a single incentive that is cited by more than $50 \%$ of the respondents including monetary incentives. In the parent study, the issue of incentives had been debated and there had been significant buy-in among those who were responding. It is therefore possible that more would have shown desire for incentive, had the questions been asked at the beginning of the implementation of the parent study, or applied to a group of potential volunteers. On the other hand, this type of incentives cited, might still have remained the same as shown in this study. The usefulness of the program was looked at from the volunteer's perception of the value of three EmONC components, that is, HBLSS training, community mobilization, and health facility improvement. The volunteers were informed that the potential outcomes of the program include reduction in deaths of mothers and their newborns, increased antenatal clinic attendance and increased numbers of deliveries within the health facility conducted by skilled birth attendants. The volunteers therefore agreed that one of the benefits of the program would be education of the community regarding maternal and newborn health. This is evidenced by the finding that $55.1 \%$ of their responses cited this as a possible benefit. Furthermore they observed that the HBLSS was useful as the communities formulate birth plans for pregnant women within their villages and encouraged them to deliver within a health facility.

These findings agree with the conclusions in the systematic review by Bhattacharyya et al, where it was noted that there is no incentive package for CHW that is universally applicable and recommended ${ }^{13}$. On the other hand, many factors were found to influence motivation of CHWs. Being part of the larger cultural and political environment, their motivation is influenced by who they are within the community including their inherent characteristics such as age, gender, ethnicity and perceived economic status. When given a large number of tasks they could become overwhelmed. Complex tasks need training and practice with less time to implement. When the area they cover is large, time requirements and lack of adequate transportation became prohibitive. The same review found that incentives 
are critical. These included supportive supervision, appropriate training, small items like badges that increase a sense of pride and status in their communities, appropriate job aids, such as counselling cards, peer support achieved through working in groups and worker associations. However, the most critical was the relationship with their communities. The EmONC study provided an opportunity for a strong relationship between the volunteers and their communities. Implementation of the community mobilization component was purely community owned. It is unclear why the strong relationship did not result in volunteer retention in this program.

Allowances, some aspects of free medicines, health education and food rations seemed to be cited more by the older population compared to the younger. This may be an indication that incentives vary with age, and the older age group had their own unique preferences while the younger ones were more flexible.

Males desired bicycles, durable health care structures and food rations, compared to the females. Females did not desire any incentive cited significantly more compared to the male volunteers. This may in part be a reflection of their decision making position in terms of capital investment in the community.

\section{Conclusion}

Recognition of the positive contribution of the program to a community alone does not seem to create desire by volunteers to remain actively engaged in a community program. When continuous attrition of volunteers from community programs occurs, replacement, retraining and service disruptions are unsustainably expensive. On the other hand, each community is unique and the challenges as well as opportunities it provides are thus community specific. Incentives are context specific ${ }^{14}$, and each community's background needs to be studied to identify and apply the acceptable ones for the given community. By exploring attitudes towards small incentives in a given context, it is possible to identify those that can be applicable and relevant. In Western Kenya, age and the gender specific incentives are were found.

\section{Recommendations}

1.) Due to the varied incentives cited, some varying with age and gender, it is important that a program considering use of volunteers,

African Health Sciences Vol 13 Issue 2 June 2013 discussed the alternative non-monetary incentives for retaining them. This discussion should involve the community, especially the potential volunteers before or during recruitment.

2.) Identification of specific needed incentives in a community should be done before any are introduced in community based programs.

\section{Acknowledgment}

Research reported in this publication was supported by the Eunice Kennedy Shriver National Institute of Child Health \& Human Development of the National Institutes of Health under Award Number U01 HD058326 and U01 HD040636. The content is solely the responsibility of the authors and does not necessarily represent the official views of the National Institutes of Health.

\section{References}

1. Perez F, Ba H, Dastagire SG, Altmann M. The role of community health workers in improving child health programmes in Mali. BMC Int Health Hum Rights. 2009;9:28. Epub 2009/11/12.

2. Iipinge S, Dambisya YM, Loewenson R, Chimbari M, Ndetei D, Munga M, Sibandze S, Lugina H (2009) Policies and incentives for health worker retention in east and southern Africa: Learning from country research. University of Namibia, Training and Research Support Centre, University of Limpopo, EQUINET, ECSAHC, EQUINET Discussion Paper 78 EQUINET: Harare.

3. Rahman SM, Ali NA, Jennings L, Seraji MH, Mannan I, Shah R, et al. Factors affecting recruitment and retention of community health workers in a newborn care intervention in Bangladesh. Hum Resour Health. 2010;8:12.

4. Nkowane AM, Boualam L, Haithami S, El Sayed el TA, Mutambo H. The role of nurses and midwives in polio eradication and measles control activities: a survey in Sudan and Zambia. Hum Resour Health. 2009;7:78.

5. Ridde V, Diarra A. A process evaluation of user fees abolition for pregnant women and children under five years in two districts in Niger (West Africa). BMC Health Serv Res. 2009;9:89. Epub 2009/06/06.

6. Buykx P, Humphreys J, Wakerman J, Pashen D. Systematic review of effective retention incentives for health workers in rural and remote areas: towards evidence-based policy. Aust J Rural Health. 2010;18(3):102-9. Epub 2010/06/ 29. 
7. McClure EM, Wright LL, Goldenberg RL, Goudar SS, Parida SN, Jehan I, et al. The global network: a prospective study of stillbirths in developing countries. Am J Obstet Gynecol. 2007;197(3):247 e1-5. Epub 2007/09/11.

8. Pasha O, Goldenberg RL, McClure EM, Saleem S, Goudar SS, Althabe F, et al. Communities, birth attendants and health facilities: a continuum of emergency maternal and newborn care (the global network's EmONC trial). BMC Pregnancy and Childbirth. 2010;10(1):82.

9. Sibley L, Buffington ST, Tedessa L, Sr., McNatt K. Home-Based Life Saving Skills in Ethiopia: an update on the second phase of field testing. Journal of midwifery \& women's bealth. 2006;51(4):284-91. Epub 2006/07/04.

10. Sibley L, Buffington ST, Haileyesus D. The American College of Nurse-Midwives' homebased lifesaving skills program: a review of the Ethiopia field test. Journal of midwifery \& women's health. 2004;49(4):320-8. Epub 2004/07/09.

11. Sibley L, Buffington ST, Beck D, Armbruster D. Home based life saving skills: promoting safe motherhood through innovative communitybased interventions. Journal of midwifery \& women's bealth. 2001;46(4):258-66. Epub 2001/10/18.
12. Dynes M, Rahman A, Beck D, Moran A, Pervin J, Yunus M, et al. Home-based life saving skills in Matlab, Bangladesh: a process evaluation of a community-based maternal child health programme. Midwifery. 2011;27(1):15-22.

13. Bhattacharyya $\mathrm{K}$, Winch $\mathrm{P}$, LeBan $\mathrm{K}$, Tien $\mathrm{M}$. Community Health Worker Incentives and Disincentives: How They Affect Motivation, Retention, and Sustainability. 2001:1-68.

14. Dieleman M, Gerretsen B, van der Wilt GJ. Human resource management interventions to improve health workers' performance in low and middle income countries: a realist review. Health Res Policy Syst. 2009;7:7.

15. WHO Making pregnancy safer: the critical role of the skilled attendant : a joint statement by WHO, ICM and FIGO. Geneva 2004

16. Willis-Shattuck M, Bidwell P, Thomas S, Wyness L, Blaauw D, Ditlopo P. Motivation and retention of health workers in developing countries: a systematic review. BMC Health Serv Res. 2008;8:247. Epub 2008/12/06.

17. Kenya National Bureau of Statistics (KNBS) and ICF Macro. 2010. Kenya National Demographic and Health Survey 2008-09, Maryland: KNBS and ICF Macro. 25. 